\title{
Outcomes after Endoscopic Dacryocystorhinostomy in the Pediatric Population
}

\author{
Henry P Barham ${ }^{1,2^{*}}$, Christian A Hall ${ }^{1,2}$, Harry E Zylicz ${ }^{1,2}$, Mohamed A Taha ${ }^{2,3}$, Margaret B \\ Westbrook $^{1,2}$, Colin J Shortess ${ }^{1,2}$, Megan M Stevenson ${ }^{1,2}$, Brittany A Zito ${ }^{1,2}$ and Blake A Booth ${ }^{4}$ \\ ${ }^{1}$ Sinus and Nasal Specialists of Louisiana, USA \\ ${ }^{2}$ Baton Rouge General Medical Center, USA \\ ${ }^{3}$ Department of Otorhinolaryngology, Cairo University, Egypt \\ ${ }^{4}$ Williamson Eye Center, USA
}

*Corresponding author: Henry P Barham, Sinus and Nasal Specialists of Louisiana, Rhinology and Skull Base Research Group, Baton Rouge, Louisiana, USA.

To Cite This Article: Henry P Barham, Outcomes after Endoscopic Dacryocystorhinostomy in the Pediatric Population. 2020 - 7(5). AJBSR. MS.ID.001197. DOI: 10.34297/AJBSR.2020.07.001197.

Received: 㘹 February 18, 2020; Published: 㘹 March 02, 2020

\begin{abstract}
Introduction: A growing body of evidence demonstrates that endonasal endoscopic dacryocystorhinostomy (eDCR) techniques provide comparable results to conventional external techniques in the adult population. The purpose of this study was to evaluate safety and outcomes of powered endoscopic DCR for the management of nasolacrimal duct obstruction in the pediatric population.
\end{abstract}

Methods: A retrospective review was performed of pediatric patients with epiphora secondary to both congenital and acquired nasolacrimal duct obstruction who underwent endoscopic DCR from August 2016 to July 2019 at a tertiary referral medical center. Operative and post-operative safety was assessed by intraoperative complications and post-operative pain requiring additional analgesia, crusting, bleeding, and revision rates. Main outcome measures were subjective improvement in epiphora and assessment of anatomic patency based on endoscopic evaluation.

Results: A total of 22 patients (age 9.14 years; 55\% female), totaling 25 primary procedures, were available at a mean follow-up of 15 (range 12 - 22) months. There were no operative or post-operative safety issues. At the most recent follow up, mild intermittent postoperative epiphora or complete resolution of epiphora was noted in $100 \%$ (25/25) of procedures; complete resolution was recorded in $92 \%$ (23/25) of procedures. Anatomic patency based on endoscopic evaluation was noted in 100\% (25/25) of procedures. $0 \%(0 / 22)$ of patients required revision DCR.

Conclusion: Results of endoscopic DCR in the pediatric population compare favorably to previously reported outcomes of success rate of adults. These results suggest consistent long-term relief of epiphora without additional risk of complication.

\section{Introduction}

Nasolacrimal duct obstruction in the pediatric population can be from a congenital or acquired cause. Congenital nasolacrimal duct obstruction (CNLDO) from the incomplete canalization of the valve of Hasner occurs in up to $6 \%$ of newborns. Acquired obstruction can occur from traumatic events, foreign body impaction or sinusitis. This obstruction predisposes children the pediatric acute dacryocystitis (PAD). Signs and symptoms of PAD include rapid edema and erythema over the medial canthal region of the lacrimal sac, epiphora or mucopurulent discharge, tenderness and fever.
Mean age of presentation is 1 week to 3.5 years and tends to have a female predominance. Most common organisms are gram-positive bacterium, Staphylococcus aureus and Streptococcus pneumonia as well as the gram-negative bacterium Hemophilus influenzae. Urgent treatment with hospital admission and broad-spectrum IV antibiotics is required. PAD may be associated with dacryocele in neonates and infants, and in general tends to have a more rapid and progressive course. A lacrimal abscess can develop which can lead to orbital cellulitis, orbital abscess or meningitis, which may threaten vision or life. 
Some children with CNLDO end up with recurrent or chronic dacryocystitis that does not respond to conservative management with massages, irrigation, and nasal probing. While dacryocystorhinostomy (DCR) is routinely performed in adults for nasolacrimal duct obstruction with success rates of $90 \%$, it remains controversial in the pediatric population since conservative measures are usually successful. There is a high rate of spontaneous resolution of epiphora in CNLDO within the first 9-12 months of life. DCR is indicated in children with chronic dacryocystitis or those who have failed conservative measures. DCR in children poses a challenge because of narrow anatomical confines, differences in anatomical boundaries, unclear roles of adjunctive therapy, and the need for special instrumentation. Dacryocystorhinostomies can be performed by external, endoscopic or transcanalicular approaches [1-8]. Much of the literature does not report a need for DCR in pediatric patients with $\mathrm{PAD}$, however, newer data indicates that pediatric DCR is becoming a well-established modality for treating recurrent PAD refractory to other treatment.

There are many advantages of endoscopic DCR: no skin incisions, preservation of the lacrimal pump, 360 degrees mucosa to mucosa anastomoses to reduce ostium scarring and postoperative morbidity. Endoscopic DCR allows for direct visualization of the lacrimal sac and common internal punctum. The procedure is typically performed with a team including both an otolaryngologist and an ophthalmologist. DCR has a success rate of $80-90 \%$ with most failures secondary to cicatricial closure of osteomy. Silicon stenting is controversial. Most place it when there is significant stenosis or in revision cases. Reports on pediatric endoscopic DCR are limited in the literature. The purpose of this study was to evaluate safety and outcomes of powered endoscopic DCR for the management of nasolacrimal duct obstruction with resulting epiphora in the pediatric population.

\section{Methods}

A retrospective review was performed of consecutive pediatric patients with epiphora secondary to both congenital and acquired nasolacrimal duct obstruction, undergoing endoscopic DCR without mucosal flap preservation from August 2016 to July 2019 at a tertiary referral medical center. Our standard preoperative evaluation included a complete history and physical examination, probing of canaliculi, lacrimal irrigation, and nasal endoscopy. Jones test, dacryocystography, and lacrimal scintigraphy were not routinely used. Exclusion criteria included history of vasculitis, primary neoplasm of the nasolacrimal system, and follow-up of less than 12 months. Patients having undergone prior external DCR and/or endoscopic DCR were not excluded from this study. Patients requiring septoplasty or concurrent endoscopic sinus surgery were included in the study.
Operative and post-operative safety was assessed by intraoperative complications, post-operative pain requiring additional analgesia, crusting, bleeding and revision rates. All procedures were performed by the primary author using the technique described in the following section. Follow-up was obtained by postoperative clinic visits. Main outcome measures were subjective improvement in epiphora and assessment of anatomic patency based on lacrimal irrigation and endoscopic evaluation. Subjective outcomes analysis included the assessment of epiphora or tearing at preoperative and postoperative visits, using a modified Munk grading system (Table 1). Mild intermittent postoperative epiphora was defined as tearing that occurs periodically and reported by the patient as not bothersome. This subjective epiphora scale is not a validated instrument but widely employed as a standard approach by our oculoplastics team and their colleagues. This study was approved by the Institutional Review Board of the Baton Rouge General Medical Center.

Statistical analysis was performed using IBM SPSS Statistics for Windows version 22 (IBM Corp., Armonk, NY). Descriptive data presented as percentages and means \pm standard deviation (SD). Kendall's tau-B was used for ordinal values. Chi square analysis was used for relationships of nominal variables. Student $t$ test (2-tailed) used for comparisons of parametric data. Results were deemed significant with a $p$ value of $<0.05$.

\section{Surgical Technique}

The surgical approach used is based on the technique described by Wormald [9], with select modifications. Only the relevant modifications in technique will be emphasized. After elevation of the mucosal flap overlying the frontal process of the maxilla, the flap is trimmed or debulked with either fine-cutting forceps or a microdebrider blade. The trimming of the mucosal flap contrasts with the technique of mucosal flap preservation favored by Wormald. Next, extensive bone removal and lacrimal sac exposure is achieved using a high-speed diamond burr. A lacrimal probe is inserted into either the upper or the lower canaliculus to tent the medial wall of the lacrimal sac and verify adequate bone removal while allowing the oculoplastics team to also confirm upper lacrimal system patency. The lacrimal sac is opened sharply both vertically and horizontally, creating anteriorly and posteriorly based flaps. The redundant lacrimal sac edges are trimmed sharply using either fine-cutting forceps, microscissors, or a smalldiameter microdebrider blade. It is imperative that the dissection is sufficiently wide enough for complete visualization of the common internal punctum. Exposure of the common internal punctum is the primary goal of any successful DCR procedure. In this series, silicone lacrimal intubation stents were not placed in any patient. Nasal packing was not used in this series and routine post-operative care included nasal saline irrigations (Table 1). 
Table 1: Modified Munk grading system for epiphora.

\begin{tabular}{|c|c|}
\hline Grade & Epiphora \\
\hline 0 & None \\
\hline 1 & Mild Intermittent \\
\hline 2 & Mild Persistent \\
\hline 3 & Moderate Persistent \\
\hline 4 & Severe Constant \\
\hline
\end{tabular}

\section{Results}

A total of 22 patients were included in the study, totaling 25 primary procedures. Patient characteristics are included in Table 2. The mean follow-up time was 15 months, with follow-up ranging from 12-22 months. There were no operative or post-operative safety issues. The patient ages ranged from 3 to 17 years with a mean patient age of 9.14 years. Three patients had bilateral DCR. Pre-operatively, 54.5\% (12/22) patients were diagnosed with epiphora, 27.3\% (6/22) were diagnosed with dacryocystitis and $18.2 \%(4 / 22)$ were diagnosed with a dacryocystocele. At most recent follow up 92\% (23/25) of procedures resulted in complete resolution of epiphora. Mean pre-operative epiphora score was 3.05 and post-operative score was 0.09 . Mean pre-operative and post-operative epiphora is depicted in Figure 1. 100\% of patients had anatomic patency on endoscopic evaluation and none of the patients required revision DCR.

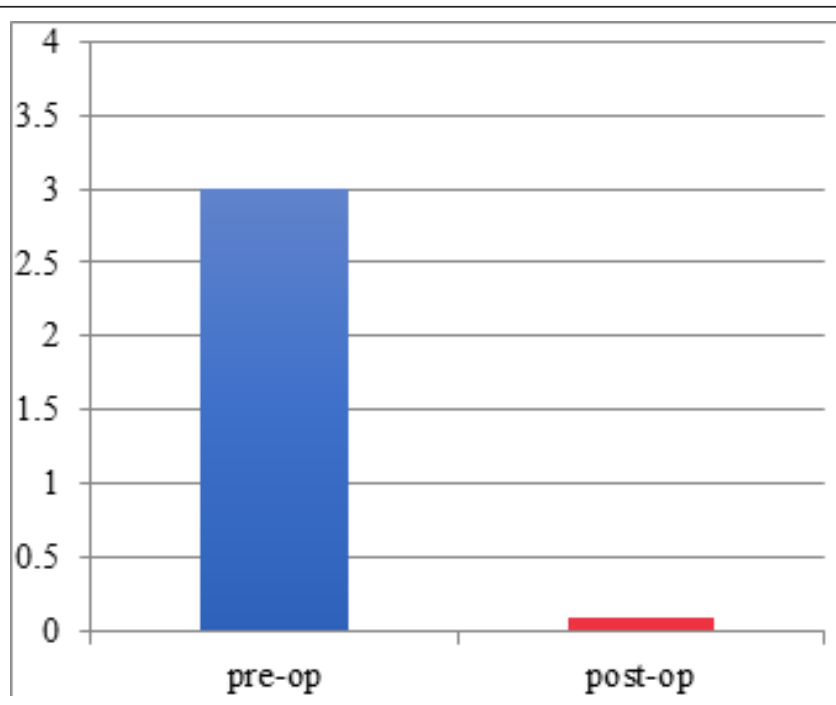

Figure 1: Pre-operative and post-operative epiphora.

\begin{tabular}{|c|c|c|c|c|c|c|c|}
\hline Patient & Sex & Age (yrs) & Procedure & Diagnosis & Pre-op score & Follow up (months) & Follow up score \\
\hline 1 & $\mathrm{~F}$ & 3 & Right DCR & Dacryocystitis & 2 & 14 & 0 \\
\hline 2 & $\mathrm{~F}$ & 13 & Right DCR & Epiphora & 3 & 16 & 1 \\
\hline 3 & $\mathrm{~F}$ & 4 & Bilateral DCR & Epiphora & 4 & 12 & 0 \\
\hline 4 & M & 14 & Right DCR & Dacryocystocele & 2 & 22 & 0 \\
\hline 5 & M & 6 & Left DCR & Epiphora & 3 & 13 & 0 \\
\hline 6 & $\mathrm{~F}$ & 7 & Left DCR & Dacryocystitis & 3 & 15 & 0 \\
\hline 7 & $\mathrm{~F}$ & 15 & Right DCR & Epiphora & 3 & 12 & 0 \\
\hline 8 & M & 3 & Right DCR & Dacryocystitis & 4 & 14 & 0 \\
\hline 9 & M & 16 & Bilateral DCR & Dacryocystocele & 2 & 15 & 0 \\
\hline 10 & $\mathrm{~F}$ & 9 & Left DCR & Epiphora & 3 & 12 & 0 \\
\hline 11 & $\mathrm{~F}$ & 8 & Right DCR & Epiphora & 4 & 14 & 0 \\
\hline 12 & M & 6 & Right DCR & Dacryocystitis & 3 & 16 & 0 \\
\hline 13 & $\mathrm{~F}$ & 12 & Right DCR & Epiphora & 2 & 18 & 0 \\
\hline
\end{tabular}




\begin{tabular}{|l|c|c|c|c|c|c|c|}
\hline 14 & F & 6 & Left DCR & Epiphora & 4 & 20 & 0 \\
\hline 15 & M & 8 & Right DCR & Dacryocystocele & 3 & 12 & 14 \\
\hline 16 & F & 5 & Bilateral DCR & Epiphora & 3 & 16 & 0 \\
\hline 17 & F & 8 & Left DCR & Dacryocystitis & 4 & 14 & 1 \\
\hline 18 & M & 9 & Right DCR & Epiphora & 3 & 15 & 0 \\
\hline 19 & M & 13 & Left DCR & Dacryocystitis & 4 & 18 & 0 \\
\hline 20 & M & 17 & Right DCR & Dacryocystocele & 2 & 3 & 0 \\
\hline 21 & F & 11 & Right DCR & Epiphora & 3 & 3 & 0 \\
\hline
\end{tabular}

There were no major complications in this series. One patient suffered from canaliculitis 2 weeks after surgery and was managed successfully with oral antibiotics. Though partially-obstucting granulation tissue was noted in 2 patients at the first post-op visit, both patients had resolution of granulation endoscopically at the 4 week follow up. There were no intraoperative complications.

\section{Discussion}

Reports of endoscopic DCR in children are limited in the literature. Advances in endoscopic techniques have greatly enhanced surgical access to the nasal cavity. Historically, patients who failed conservative management nasolacrimal duct obstruction received external DCR with success rates of $90 \%$. Endoscopic DCR has been shown to be a successful alternative to external DCR with similar success rates. Success rates in primary endoscopic DCR to be between $88-92 \%$ with anatomic success rate in all cases with a clinical success rate, as defined by the resolution of epiphora, of $92 \%$. Complete clinical resolution of epiphora in $88 \%$ of patient [10-19].

Endoscopic DCR allows for a less invasive approach with no skin incision and subsequent scar. It also causes less surgical trauma to the medial canthus and orbital tissues as well as less bleeding than seen in external approaches. Possible complications of endoscopic DCR are similar to those of external DCR and include failure of the procedure, hemorrhage, the development of a granuloma around the ostium, herniation of the orbital fat, orbital and subcutaneous emphysema and formation of a conjunctival fistula. With the advances in endoscopic techniques the rate of complications in the literature is very low $[20,21]$.

Based on our experience, endoscopic DCR can successfully be performed in children without additional complications. We found a success rate of $100 \%$ improvement and $92 \%$ complete resolution, which is comparable to that seen in the adult population. Our results provide data that endoscopic DCR may be safely performed in the pediatric population with great success regardless of underlying diagnosis to treat both congenital and acquired obstruction of the nasolacrimal system.

\section{Conclusion}

Results of endoscopic DCR in the pediatric population compare favorably to the previously reported outcomes of success rate of adults. These results suggest consistent long-term relief of epiphora without additional risk of complication.

\section{References}

1. Hartikainen J, Antila J, Varpula M, Puukka P, Seppä H, et al. (1998) Prospective randomized comparison of endonasal endoscopic dacryocystorhinostomy and external dacryocystorhinostomy. Laryngoscope 108(12): 1861-1866.

2. Welham R, Wulc A (1987) Management of unsuccessful lacrimal surgery. Br J Ophthalmol 7(2): 152-157.

3. McDonogh M (1992) Endoscopic transnasal dacryocystorhinostomy Results in 21 patients. S Afr J Surg 30(3): 107-110.

4. Barmettler A, Ehrlich JR, Lelli G (2013) Current preferences and reported success rates in dacryocystorhinostomy amongst ASOPRS members. Orbit 32(1): 20-26.

5. Tsirbas A, Davis G, Wormald PJ (2004) Mechanical endonasal dacryocystorhinostomy versus external dacryocystorhinostomy. Ophthal Plast Reconstr Surg 20(1): 50-56.

6. Ben Simon GJ, Joseph J, Lee S, Schwarcz RM, McCann JD, et al. (2005) External versus endoscopic dacryocystorhinostomy for acquired nasolacrimal duct obstruction in a tertiary referral center. Ophthalmology 112(8): 1463-1468.

7. Cokkeser Y, Evereklioglu ERH (2000) Comparative external versus endoscopic dacryocystorhinostomy: Results in 115 patients (130 eyes) Otolaryngol Head Neck Surg 123(4): 488-491.

8. Yigit O, Samancioglu M, Taskin U, Ceylan S, Eltutar K, et al. (2007) External and endoscopic dacryocystorhinostomy in chronic dacryocystitis: comparison of results. Eur Arch Otorhinolaryngol 264(8): 879-885.

9. Wormald PJ (2002) Powered endoscopic dacryocystorhinostomy. Laryngoscope 112(1): 69-72.

10. Tsirbas A, Wormald PJ (2003) Endonasal dacryocystorhinostomy with mucosal flaps. Am J Ophthalmol 135(1): 76-83.

11. Ramakrishnan VR, Hink EM, Durairaj VD, Kingdom TT (2007) Outcomes after endoscopic dacryocystorhinostomy without mucosal flap preservation. Am J Rhinol 21(6): 753-757.

12. Mann BS, Wormald PJ (2006) Endoscopic assessment of the dacryocystorhinostomy ostium after endoscopic surgery. Laryngoscope 116(7): 1172-1174.

13. Linberg JV, Anderson RL, Busted RM, Barreras R (1982) Study of intranasal ostium external dacryocystorhinostomy. Arch Ophthalmol 100(11): 1758-1762. 
14. Deka A, Bhattacharjee K, Bhuyan SK, Barua CK, Bhattacharjee $\mathrm{H}$, et al. (2006) Effect of mitomycin C on ostium in dacryocystorhinostomy. Clin Exp Ophthalmol 34(6): 557-561.

15. Hodgson N, Bratton E, Whipple K, Priel A, Oh SR, et al. (2014) Outcomes of endonasal dacryocystorhinostomy without mucosal flap preservation. Ophthal Plast Reconstr Surg 30(1): 24-27.

16. Massegur H, Trias E, Adema JM (2004) Endoscopic dacryocystorhinostomy: Modified technique. Otolaryngol Head Neck Surg 130(1): 39-46.

17. Metson R (2001) Dacryocystorhinostomy. In: Kennedy DW, Bolger WE, Zinreich SJ (Eds.), Diseases of the Sinuses: Diagnosis and Management. BC Decker, Hamilton Ontario Canada pp. 317-324.

18. Yoon SW, Yoon YS, Lee SH (2006) Clinical results of endoscopic dacryocystorhinostomy using a microdebrider. Korean J Ophthalmol 20(1): 1-6.
19. Kumar S, Mishra AK, Sethi A, Mallick A, Maggon N, et al. (2018) Comparing outcomes of the standard technique of endoscopic DCR with its modificatioons: a retrospective analysis. Otolaryngol Head Neck Surg 160(2): 347-354

20. Mansour K, Blanksma LJ, Vrakking H, Jager PL (2008) Scintigraphic evaluation for tear drainage, after dacryocystorhinostomy, in relation to patient satisfaction. Eye 22(3): 414-419.

21. Longari F, Dehgani Mobaraki P, Ricci AL, Lapenna R, Cagini C, et al. (2016) Endoscopic dacryocytorhinostomy with and without silicone intubation: 4 years retrospective study. Eur Arch Otorhinolaryngol 273(8): 2079-2084. 